\title{
Carboxymethylcellulose acetate butyrate/poly(4-vinyl- $N$-pentyl pyridinium bromide) blends as antimicrobial coatings
}

\author{
L. S. Blachechen ${ }^{1}$, J. Amim Jr. ${ }^{1,2}$, N. Lincopan ${ }^{3,4}$, D. F. S. Petri ${ }^{1 *}$ \\ ${ }^{1}$ Instituto de Química, Universidade de São Paulo, São Paulo, Brazil \\ ${ }^{2}$ Instituto de Química, Universidade Federal do Rio de Janeiro, Campus Macaé, Brazil \\ ${ }^{3}$ Instituto de Ciências Biomédicas, Universidade de São Paulo, São Paulo, Brazil \\ ${ }^{4}$ Faculdade de Ciências Farmacêuticas, Universidade de São Paulo, São Paulo, Brazil
}

Received 17 January 2015; accepted in revised form 10 April 2015

\begin{abstract}
Blends of carboxymethyl cellulose acetate butyrate (CMCAB), a cellulose derivative, and poly(4-vinyl- $N$-pentyl pyridinium bromide) (QPVP-C5), an antimicrobial polymer, were prepared by casting method and characterized by means of Fourier transform infrared vibrational spectroscopy (FTIR), scanning electron microscopy (SEM), thermogravimetric analysis (TGA), differential scanning calorimetry (DSC) and contact angle measurements. Miscibility between CMCAB and QPVP-C5 was evidenced by DSC measurements of blends, which showed a single thermal event of $T_{\mathrm{g}}$, and SEM images, which revealed homogenous morphology, regardless the blend composition. Moreover, thermal stability of QPVP-C5 was substantially enhanced, when it was mixed with CMCAB. Upon increasing the QPVP-C5 content in the blend the wettability and antimicrobial activity against Gram-positive bacteria Micrococcus luteus increased, indicating the surface enrichment by pyridinium groups. In fact, blends with $70 \mathrm{wt} \%$ QPVP-C5 reduced $5 \log$ and $4 \log$ the colony-forming units of Micrococcus luteus and Escherichia coli, respectively.
\end{abstract}

Keywords: coatings, carboxymethylcellulose acetate butyrate, poly(4-vinyl-N-pentyl pyridinium bromide), antimicrobial properties, blends

\section{Introduction}

Carboxymethylcellulose acetate butyrate (CMCAB) is a cellulose ester often applied as coating for cellulosic substrates, matrix component of compression tablets or support for biomolecules [1-5]. Although $\mathrm{CMCAB}$ has been successfully used as coating material, it could be improved to gain antimicrobial property. Such property might be achieved by immobilizing lysozyme, an enzyme that catalyzes the hydrolysis of peptidoglycans on bacterial cell walls, on the surface of CMCAB, so that the catalytic activity is high enough to kill bacteria, even after many cycles of use [5]. The incorporation of antimicrobial agents, like silver ions or silver nanoparticles [6, 7], antibiotics or quaternary ammonium compounds (QAC) [8], to polymeric matrices is also a common strategy to obtain polymeric surfaces with microbiocidal activity. Particularly the polymers containing QAC in the backbone or sidechains, such as chitosan $[9,10], N$-alkyl polyethyleneimines $[11,12]$ and poly(4-vinyl- $N$-alkylpyridinium bromide) with alkyl chains shorter than six carbons [13-18], have been applied as bactericidal materials. The mechanism of their biocide action is well reported in the literature $[14,19-21]$. The adsorption of bacteria onto cationic surfaces is driven by electrostatic interac-

\footnotetext{
${ }^{*}$ Corresponding author, e-mail: dfsp@iq.usp.br

(C) BME-PT
} 
tion between polymer cationic charges and the bacterial membranes negative charges (teichoic acids of Gram-positive bacteria and negatively charged phospholipids at the outer membrane of Gram-negative bacteria). Upon adsorbing, the compensation of the negative charges of the bacterial envelope is provided by the cationic charges of the substrate, and the bacteria lose their natural counter ions, which are released, increasing the entropic gain. Thus, solid substrate becomes biocidal when the number of cationic sites is large enough to remove counter ions from bacteria, inducing disruption of the bacteria envelope. Moreover, if the polycation chains have hydrophobic side chains, the disruption of outer and cytoplasmic membranes is favored.

Considering the demand for long-lasting antimicrobial coatings based on environmentally friendly and non-toxic products [22], blends of CMCAB and poly(4-vinyl- $N$-pentylpyridinium bromide), QPVPC5, were prepared by casting in a broad composition range. The morphological structure, miscibility, thermal behavior and wettability were investigated by means of scanning electron microscopy (SEM), differential scanning calorimetry (DSC), thermogravimetric analysis (TGA) and contact angle measurements, respectively. Antimicrobial properties of neat $\mathrm{CMCAB}$ and $\mathrm{CMCAB} / \mathrm{QPVP}-\mathrm{C} 5$ blends against Gram-positive bacteria Micrococcus luteus were assessed by changes of microbial dispersions turbidity. Moreover, the ability to reduce the colonyforming units (CFU) of Micrococcus luteus and Escherichia coli was quantitatively evaluated for neat CMCAB and CMCAB/QPVP-C5 blends.

\section{Experimental section}

\subsection{Materials}

Carboxymethyl cellulose acetate butyrate (CMCAB641-0.2) $\left(\bar{M}_{\mathrm{n}}=20000 \mathrm{~g} \cdot \mathrm{mol}^{-1} ; D S_{\mathrm{Ac}}=0.4 ; D S_{\mathrm{Bu}}=\right.$ 1.6 and $D S_{\mathrm{CM}}=0.3$ ), was kindly supplied by Eastman Chemical Co. (Brazil). The chemical structure of

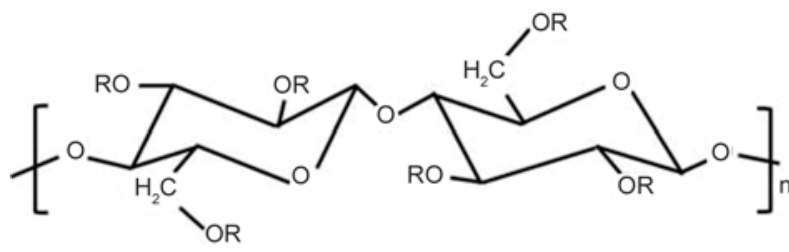

Figure 1. Representation of chemical structures of $\mathrm{CMCAB}$, where $\mathrm{R}$ refers to $\mathrm{H}, \mathrm{COCH}_{3}, \mathrm{COC}_{3} \mathrm{H}_{7}$ and/or $\mathrm{CH}_{2} \mathrm{COOH}$

CMCAB is represented in Figure 1. Poly(4-vinylpyridine) (PVP, $\bar{M}_{\mathrm{w}} \sim 60000 \mathrm{~g} \cdot \mathrm{mol}^{-1}$, degree of polymerization, $D P, \sim 600$ ) and 1-bromopenthane (purity 99\%) were obtained from Sigma-Aldrich (Brazil), and anhydrous ethanol (98\%), diethyl ether (99\%) and $\mathrm{HBr}(48 \%)$ from Labsynth (Brazil). All reagents and solvents were used without previous purification. Gram-positive bacteria Micrococcus luteus (ATCC 4698) and Gram-negative bacteria Escherichia coli (ATCC25922) were purchased from Adolf Lutz Institute (Brazil).

\subsection{Preparation of poly(4-vinyl- $N$-pentyl pyridinium bromide), QPVP-C5}

Bromide salt of PVP quaternized with linear pentyl chains was prepared in a flask with a reflux condenser by dissolving PVP $(10 \mathrm{wt} \%)$ in anhydrous ethanol, adding the 1-bromopentane with an excess of 5 times the stoichiometric amount and keeping the mixture stirring under nitrogen atmosphere for $24 \mathrm{~h}$ at $60^{\circ} \mathrm{C}$ $[23,24]$, as schematically represented in Figure 2. The mixture was then precipitated in diethyl-ether to obtain a slightly yellow solid that was re-dissolved in ethanol and re-precipitated the same way. The product was washed with a cold $\mathrm{HBr} 0.1 \mathrm{~mol} \cdot \mathrm{L}^{-1}$ solution in order to remove any eventual unreacted parts, washed with diethyl-ether once more, and dried under vacuum at room temperature. The effectiveness of the quaternization was evaluated by Fourier transform infrared (FTIR) vibrational spectroscopy observing the shift of the characteristic pyri-
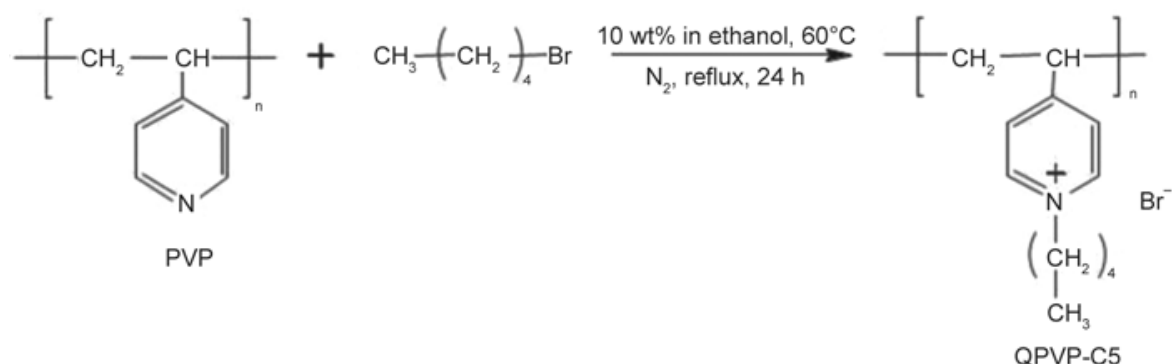

Figure 2. Schematic representation of quaternization of PVP with bromopentane 
dine $\mathrm{N}-\mathrm{C}$ stretching band from 1600 to $1640 \mathrm{~cm}^{-1}$, which is typical for pyridinium cations. The band in $1600 \mathrm{~cm}^{-1}$ disappeared entirely, indicating complete quaternization. The resulting polycation was coded as QPVP-C5.

\subsection{Preparation of CMCAB/QPVP-C5 blend films}

CMCAB/QPVP-C5 blends were prepared by dissolving the polymers in ethanol ( $1 \mathrm{wt} \%)$, which is a good solvent for both polymers and casting the solutions $(10 \mathrm{~mL})$ in polyethylene $(\mathrm{PE})$ dishes $(4 \mathrm{~cm}$ diameter) at $50^{\circ} \mathrm{C}$, during $24 \mathrm{~h}$. PE dishes were chosen because when glass Petri dishes were used for polymer film formation, the adhesion to glass surface was so strong that impeached the films removal after drying. The weight fractions $(x)$ of QPVP-C5 in the blends were $0 ; 0.17 ; 0.30 ; 0.50 ; 0.70$ and 1.0 .

\subsection{Characterization}

The CMCAB/QPVP-C5 blends films were analyzed by Fourier transform infrared vibrational spectroscopy (FTIR) in Bomem MB100 equipment, resolution of $4 \mathrm{~cm}^{-1}$. The morphology of CMCAB/ QPVP-C5 blends was analyzed by means of scanning electron microscopy with FE-SEM JEOL 7401 equipment. Cryofractured samples were coated with a thin $(2 \mathrm{~nm})$ gold layer prior to SEM analyses. Thermogravimetric analyses (TGA) of pure polymers and CMCAB/QPVP-C5 blends were carried out in TGA 2950 equipment (TA Instruments). Pt crucibles containing the samples were heated and cooled down at rate of $10^{\circ} \mathrm{C} \cdot \mathrm{min}^{-1}$, ranging from 25 up to $500^{\circ} \mathrm{C}$, under $\mathrm{N}_{2}$ atmosphere $\left(50 \mathrm{~mL} \cdot \mathrm{min}^{-1}\right)$. Glass transition temperature $\left(T_{\mathrm{g}}\right)$ of pure polymers and respective blends were determined by means of differential scanning calorimetry (DSC) in TA-DSC Q10V9.0 equipment. Each sample sealed in $\mathrm{Al}$ crucibles was heated and cooled down at rates of 15 and $20^{\circ} \mathrm{C} \cdot \mathrm{min}^{-1}$, respectively, in the temperature range from 25 to $250^{\circ} \mathrm{C}$ under dynamic $\mathrm{N}_{2}$ atmosphere $\left(50 \mathrm{~mL} \cdot \mathrm{min}^{-1}\right)$. The DSC cell was calibrated with In $\left(T_{\mathrm{m}}=157^{\circ} \mathrm{C} ; \Delta H_{\mathrm{m}}=28.54 \mathrm{~J} \cdot \mathrm{g}^{-1}\right)$ and $\mathrm{Zn}\left(T_{\mathrm{m}}=\right.$ $420^{\circ} \mathrm{C}$ ). An empty crucible was used as reference. The second heating was considered for the determination of $T_{\mathrm{g}}$ values. Contact angle measurements were performed at $(25 \pm 1)^{\circ} \mathrm{C}$ in a home-built apparatus [25]. Sessile drops of $8 \mu \mathrm{L}$ Milli-Q water were used for the advancing contact angle $\left(\theta_{\mathrm{a}}\right)$ measurements for pure polymers, QPVP-C5 and CMCAB, and CMCAB/QPVP-C5 blends films. Three samples of the same composition were analyzed at two different spots.

\subsection{Determination of biocidal action}

\subsubsection{Monitoring the turbidity of Micrococcus luteus dispersions}

The antimicrobial action of pure $\mathrm{CMCAB}$, pure QPVP-C5, and CMCAB/QPVP-C5 blends was assessed by a standard assay for the determination of lysozyme activity, as described elsewhere [26]. Briefly, the initial turbidity $\left(\tau_{\mathrm{i}}\right)$ of aqueous dispersions (pH 6) of Micrococcus luteus (ATCC 4698) at $0.5 \mathrm{mg} \cdot \mathrm{mL}^{-1}$ was determined at $25^{\circ} \mathrm{C}$ and $650 \mathrm{~nm}$, using Beckmann Coulter DU-600 spectrophotometer. Polymer films $\left(22 \mathrm{~cm}^{2}\right)$ were dipped into the $M$. luteus dispersions and allowed to interact during $1 \mathrm{~h}$. After this period of time the turbidity $\left(\tau_{\mathrm{f}}\right)$ of bacteria dispersions was measured again. Since $M$. luteus is micrometer-sized and the disruption of bacteria envelope leads to decrease in size, antimicrobial activity can be correlated with the relative decrease of turbidity $(\Delta \tau)$; the larger is $\Delta \tau$, the more efficient is the antimicrobial agent (Equation (1)):

$\Delta \tau=\frac{\tau_{\mathrm{i}}-\tau_{\mathrm{f}}}{\tau_{\mathrm{i}}} \cdot 100$

As a control experiment, $(\Delta \tau)$ values were also measured after $1 \mathrm{~h}$ for aqueous dispersions of $M$. luteus $\left(\tau_{\mathrm{i}}\right)$ in the absence of any polymer.

\subsubsection{Determination of the minimum inhibitory concentration (MIC) and minimum bactericidal concentration (MBC) of QPVP-C5 for Micrococcus luteus and Escherichia coli}

The minimum inhibitory concentration (MIC) and minimal bactericidal concentration (MBC) of QPVPC5 for E. coli (ATCC 25922) and M. luteus (ATCC 4698) were determined in triplicates by the microdilution broth method in 96-well microplates, as recommended by the CLSI [27]. In brief, twofold serial dilutions of QPVP-C5 were prepared at final volume of $0.1 \mathrm{~mL}$ of Mueller-Hinton broth per well in a 96-well microtitre plates. The final concentration of the QPVP-C5 ranged from 6000 to $0.005 \mu \mathrm{g} \cdot \mathrm{mL}^{-1}$. Each well of the microtitre plate was inoculated with bacterial cell suspension to a final concentration of $5 \cdot 10^{5} \mathrm{CFU} \cdot \mathrm{mL}^{-1}$ and the plates were incubated at $35^{\circ} \mathrm{C}$ for 16 to 20 hours in an ambient air 
incubator. MIC was defined as the lowest concentration of QPVP-C5 that completely inhibited growth of the organism (lack of turbidity) in the microdilution wells. To determine the MBC, $10 \mu \mathrm{L}$ aliquots were taken from selected wells that did not show visible bacterial growth and spread on plates containing Agar Muller-Hinton medium, being incubated for 24 hours at $37^{\circ} \mathrm{C}$. Visual observation indicated presence or absence of growth and MBC endpoint was considered as the lowest concentration of QPVP-C5 solution showing no growth.

\subsubsection{Colony forming units (CFU) count on CMCAB and CMCAB/QPVP-C5 blends}

The antibacterial activity of CMCAB and CMCAB/ QPVP-C5 blends, against M. luteus ATCC 4698 and E. coli ATCC 25922 was essentially determined as described in the JIS Z 2801:2000 standard [28]. An aliquot $(400 \mu \mathrm{L})$ of a cell suspension of either $M$. luteus ATCC $4698\left(10^{5} \mathrm{CFU} \cdot \mathrm{mL}^{-1}\right)$ or E. coli ATCC $25922\left(10^{6} \mathrm{CFU} \cdot \mathrm{mL}^{-1}\right)$ was held in intimate contact with each of the 2 replicates of the test surfaces, i.e., CMCAB or CMCAB/QPVP $(x=0.7)$ films $22 \mathrm{~mm}$ of diameter, prepared using sterile 12well flat bottom plates, for 24 hours at $37^{\circ} \mathrm{C}$, under humid conditions. Next, the size of surviving bacterial populations was determined by viable cell counts on Trypticase Soy Agar, after incubation at $37^{\circ} \mathrm{C}$ for 24 hours of $0.1 \mathrm{~mL}$ sample taken from the test surfaces. A negative control experiment (without any bacteria) was also performed.

\subsection{Quantification of QPVP-C5 leaching}

The amount of QPVP-C5 leached during antimicrobial assays was evaluated by UV-Vis analyses following the same conditions used with bacteria dispersions. Polymeric blend films were dipped in distilled water and after $1 \mathrm{~h}$ the concentration of polycation was quantified in water by measuring the absorption intensity at $\lambda=258 \mathrm{~nm}$ using Beckmann Coulter DU-600 spectrophotometer. The amount of QPVP-C5 leached was determined through an analytical curve obtained from five different concentrations of specimen at the wavelength $258 \mathrm{~nm}$, which is assigned to electronic transitions in the pyridinium ring due to the $\pi \rightarrow \pi^{*}$ electronic transition.

\section{Results and discussion 3.1. CMCAB/QPVP-C5 blends characterization}

FTIR spectra obtained for all CMCAB/QPVP-C5 blends presented the typical absorption bands observed for the corresponding pure $\mathrm{CMCAB}$ and QPVP-C5 polymers (Figure 3), namely, the $\mathrm{C}=\mathrm{O}$ stretch of cellulose ester at $1750 \mathrm{~cm}^{-1}$ and the pyridinium group at $1640 \mathrm{~cm}^{-1}$. Considering that strong acid-base interactions can cause shifts of up to $30 \mathrm{~cm}^{-1}$ in the carbonyl and carboxylic acid bands [29], the spectra in Figure 3 indicate the absence of such interactions. Liu and Xiao characterized blends of konjac glucomannan gum [30] or chitosan [31] with QPVP-C4 by means of FTIR and other analytical techniques, which evidenced intermolecular interactions between the polymers in the both blends. Whereas in the first case the stretching vibration of $-\mathrm{OH}$ in comparison to the pure konjac glucomannan gum shifted gradually to higher wavenumbers as the amount of QPVP-C4 increased, in the latter the $-\mathrm{NH}_{2}$ band of chitosan split in two denoting interaction with QPVP-C4.

The miscibility between CMCAB and QPVP-C5 was investigated by DSC analyses. The glass transition temperature $\left(T_{\mathrm{g}}\right)$ values determined for pure $\mathrm{CMCAB}$, pure QPVP-C5 and blends are presented in the Table 1. DSC curves (Figure 4a) exhibited a sin-

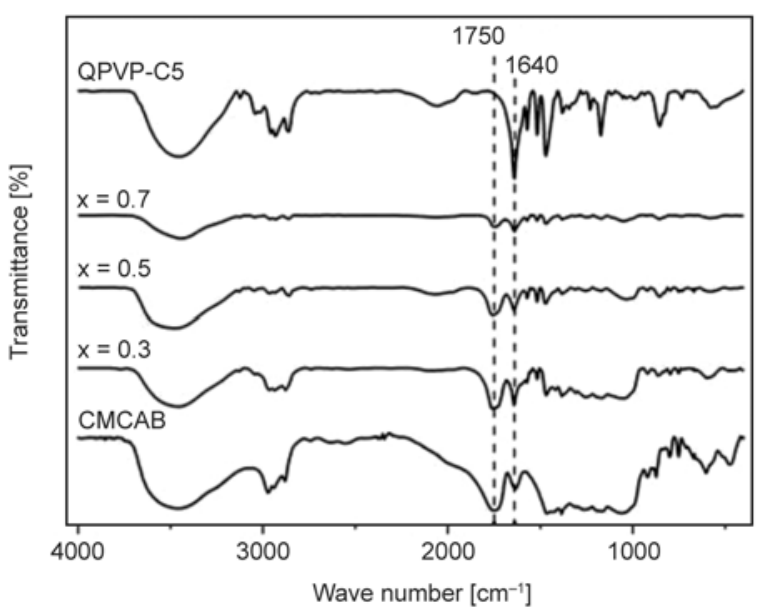

Figure 3. FTIR spectra of pure QPVP-C5 and CMCAB, and CMCAB/QPVP-C5 blends. ' $x$ ' stands for the weight fraction of QPVP-C5 in the blend. The dashed lines indicate the typical absorbance bands of pyridinium group and $\mathrm{C}=\mathrm{O}$ stretch of ester groups at 1640 and $1750 \mathrm{~cm}^{-1}$, respectively. 
Table 1. Experimental glass transition temperature $\left(T_{\mathrm{g}}\right)$, glass transition temperature calculated with Fox equation $\left(T_{\mathrm{g}}^{\mathrm{F}}\right)$, contact angle $(\theta)$ values and turbidity decrease $(\Delta \tau)$ determined for pure $\mathrm{CMCAB}$, pure QPVP-C5 and their blends. ' $x$ ' stands for weight fraction of QPVP-C5 in the blends

\begin{tabular}{|l|c|c|c|c|c|}
\hline \multicolumn{1}{|c|}{ Sample } & $\mathbf{x}$ & $\begin{array}{c}\mathbf{T}_{\mathbf{g}} \\
{[\mathbf{K}]}\end{array}$ & $\begin{array}{c}\mathbf{T}_{\mathbf{g}}^{\mathbf{F}} \\
{[\mathbf{K}]}\end{array}$ & $\begin{array}{c}\boldsymbol{\theta} \\
{\left[{ }^{\circ}\right]}\end{array}$ & $\begin{array}{c}\Delta \boldsymbol{\tau} \\
{[\mathbf{\%}]}\end{array}$ \\
\hline QPVP-C5 & - & $350.6 \pm 0.5$ & - & $*$ & $96 \pm 2$ \\
\hline CMCAB/QPVP-C5 & 0.7 & $351 \pm 1$ & 364 & $* *$ & $66 \pm 5$ \\
\hline CMCAB/QPVP-C5 & 0.5 & $370 \pm 1$ & 380 & $* *$ & $52 \pm 2$ \\
\hline CMCAB/QPVP-C5 & 0.3 & $370 \pm 1$ & 389 & $65 \pm 3$ & $30 \pm 2$ \\
\hline CMCAB/QPVP-C5 & 0.17 & - & - & $69 \pm 4$ & $10 \pm 1$ \\
\hline CMCAB & - & $419 \pm 1$ & - & $71 \pm 2$ & $3 \pm 1$ \\
\hline
\end{tabular}

Films were either $(*)$ dissolved or $(* *)$ swollen by droplets of water.

gle $T_{\mathrm{g}}$ value, indicating miscibility of systems. The $T_{\mathrm{g}}$ value of miscible polymer blends can be estimated by the Fox equation (Equation (2)) [32]:

$\frac{1}{T_{\mathrm{g}}}=\frac{x_{1}}{T_{\mathrm{g} 1}}+\frac{x_{2}}{T_{\mathrm{g}_{2}}}$

where $x_{1}$ and $x_{2}$ are the weight fraction of each polymer in the blend and $T_{\mathrm{g}_{1}}$ and $T_{\mathrm{g}_{2}}$ are the $T_{\mathrm{g}} \mathrm{s}$ of polymer $a$ and polymer $b$, respectively.

For all blends the experimental value of $T_{\mathrm{g}}$ was smaller than the predicted one, as presented in Figure $4 \mathrm{~b}$. The negative deviation from Fox equation indicates good miscibility between the two components [32]. Hydrophobic interactions between CMCAB butyl groups $\left(D S_{\mathrm{Bu}}=1.64\right)$ and QPVP-C5 pentyl groups might possibly drive the miscibility between the polymers, since no shift in the $\mathrm{C}=\mathrm{O}$ or pyridinium absorption bands could be observed in

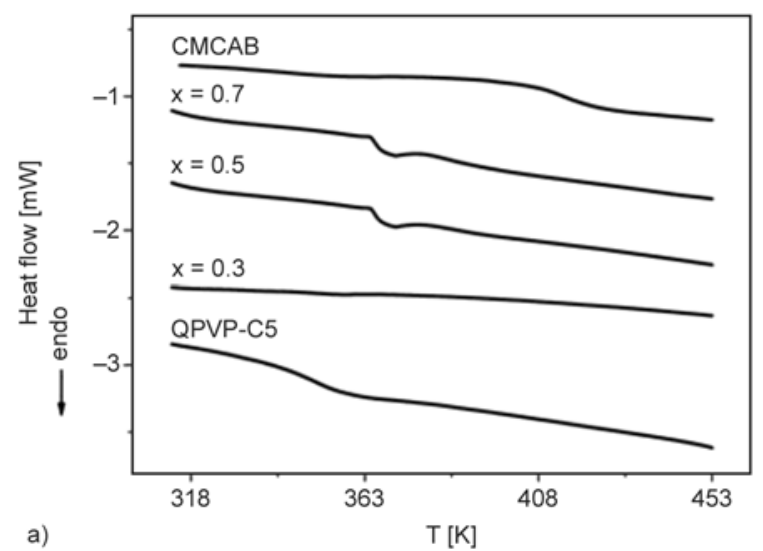

the FTIR spectra of blends in comparison to the spectra of pure polymers.

SEM images obtained for cryofractured films of pure CMCAB and QPVP-C5 (Figure 5a and 5b, respectively), and $\mathrm{CMCAB} / \mathrm{QPVP}-\mathrm{C} 5$ blends with $x=0.3 ; 0.5$ and 0.7 (Figure $5 \mathrm{c}, 5 \mathrm{~d}$ and $5 \mathrm{e}$, respectively), showed homogeneous phases in all blends composition, corroborating with the DSC results. The images in the insets allow estimating the film thickness, which ranged from $\sim 15$ to $\sim 50 \mu \mathrm{m}$.

The thermal stability of pure CMCAB and QPVP-C5 was investigated by means of thermogravimetric (TG) curves, as shown in Figure 6a. The events related to the polymers thermal behavior can be better identified in the derivatives weight loss (DTG) curves (Figure 6b). The TG and DTG curves obtained for $\mathrm{CMCAB}$ showed a weight loss stage with peak temperature at $355^{\circ} \mathrm{C}$, which can be attributed to the thermal degradation of cellulose ester and corresponded to $\sim 80 \%$ of initial weight. Between 420 and $500^{\circ} \mathrm{C}$ the weight remained constant, since the residual material ( $\sim 15 \%$ of initial weight) was mainly ashes. The TG and DTG curves obtained for QPVP-C5 indicated three stages. The first one corresponding to $\sim 10 \%$ weight loss at $59^{\circ} \mathrm{C}$ was attributed to the loss of ethanol molecules entrapped in the bulk material. The second and third stages with peak temperatures at 290 and $336^{\circ} \mathrm{C}$, respectively, were attributed to the decomposition of QPVP-C5, remaining $\sim 5 \%$ of initial weight as ashes.

The TG and DTG curves obtained for $\mathrm{CMCAB} /$ QPVP-C5 blends are presented in Figures 6c and $6 \mathrm{~d}$, respectively. The general trend is that the ther-

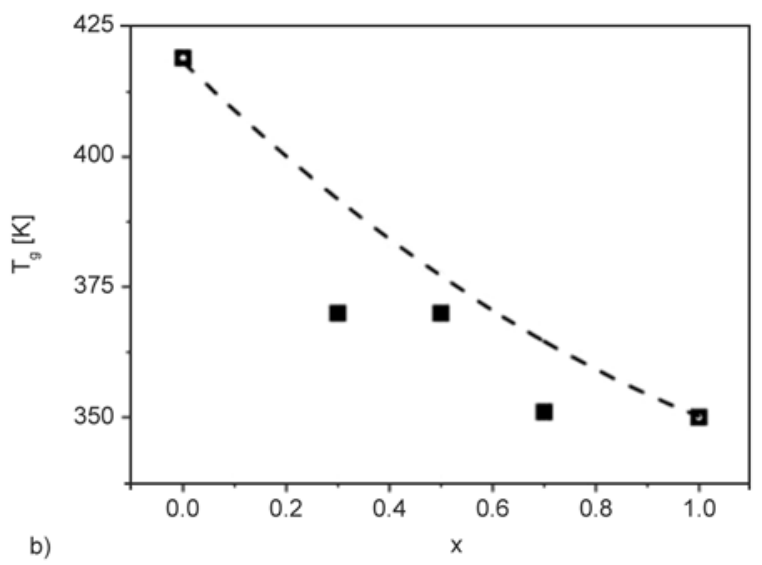

Figure 4. (a) DSC curves obtained for pure QPVP-C5, pure CMCAB, and CMCAB/QPVP-C5 blends. (b) Glass transition temperature $\left(T_{\mathrm{g}}\right)$ of pure QPVP-C5, pure CMCAB, and CMCAB/QPVP-C5 blends determined by DSC experiments (squares) and calculated (---) by Fox equation as function of weight fraction of QPVP-C5 in the blends $(x)$. 


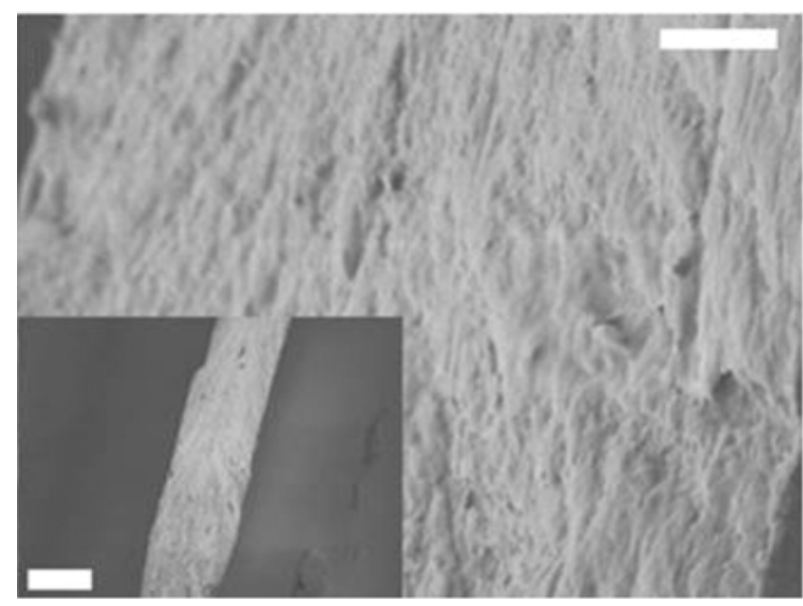

a)

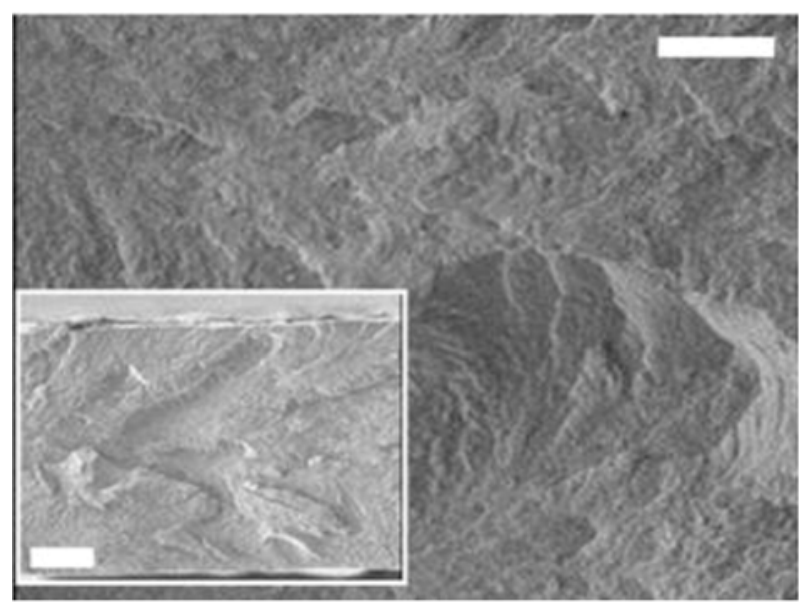

c)

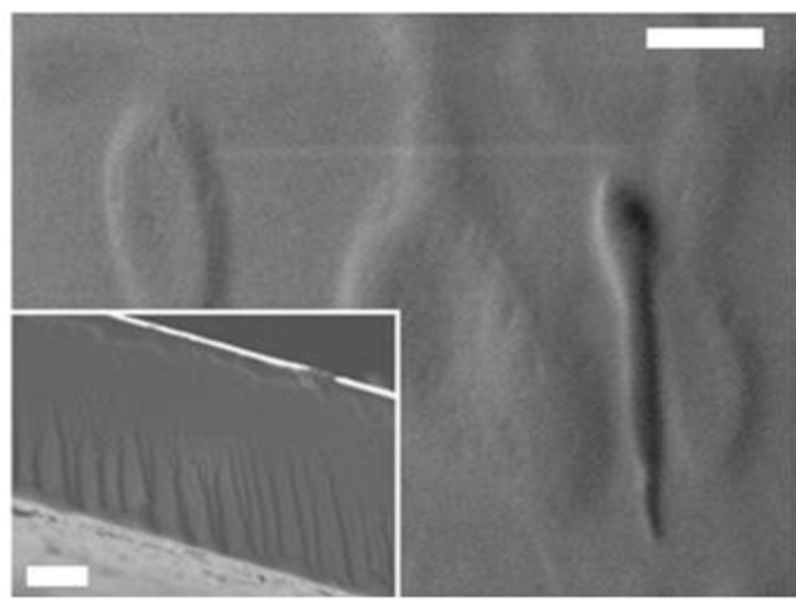

b)

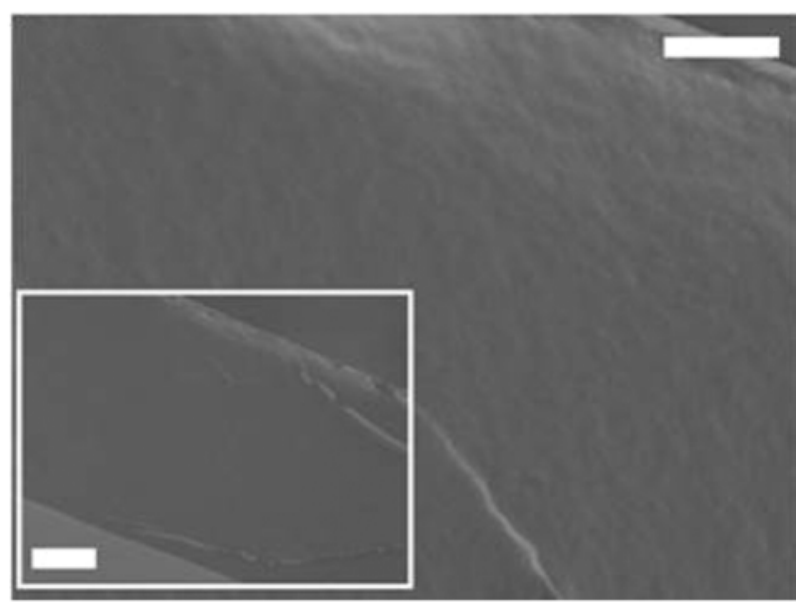

d)

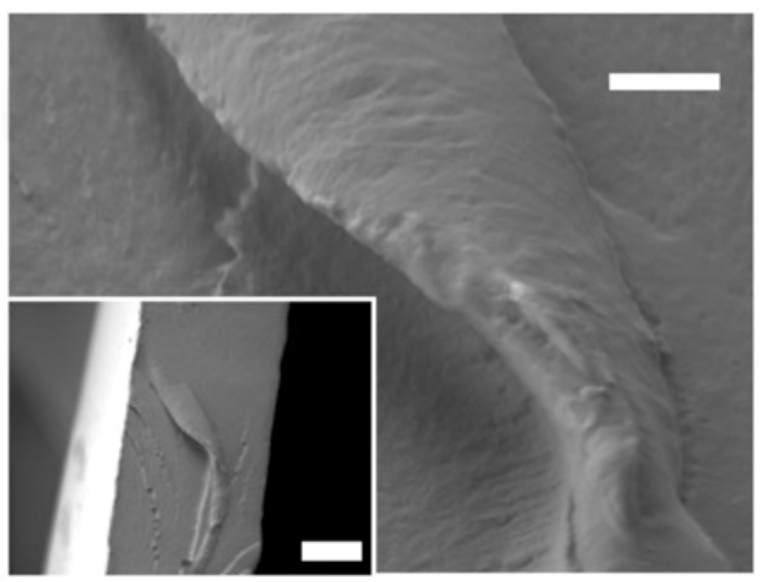

Figure 5. SEM images obtained for pure CMCAB (a), pure QPVP-C5 (b), CMCAB/QPVP-C5 blends with $x=0.3$ (c), $x=$ 0.5 (d) and $x=0.7$ (e). The scales bars correspond to $2 \mu \mathrm{m}$. The scale bars in the insets correspond to $10 \mu \mathrm{m}$.

mal stability of the blends was inferior to that of pure $\mathrm{CMCAB}$, but superior to that of pure QPVPC5. It implies that the thermal stability of QPVP-C5 is enhanced due to the introduction of the CMCAB. A similar behavior was observed for blends of QPVP$\mathrm{C} 4$ / konjac glucomannan, where the polysaccharide enhanced the blends thermostability [30].

\subsection{Antimicrobial activity of CMCAB/QPVP-C5 blends}

In general polycations are biocidal polymers, but the structural characteristics such as molecular weight, type and degree of alkylation, and distribution of charge affect the antimicrobial action [33]. For instance, the antimicrobial activity of poly(4-vynil- 

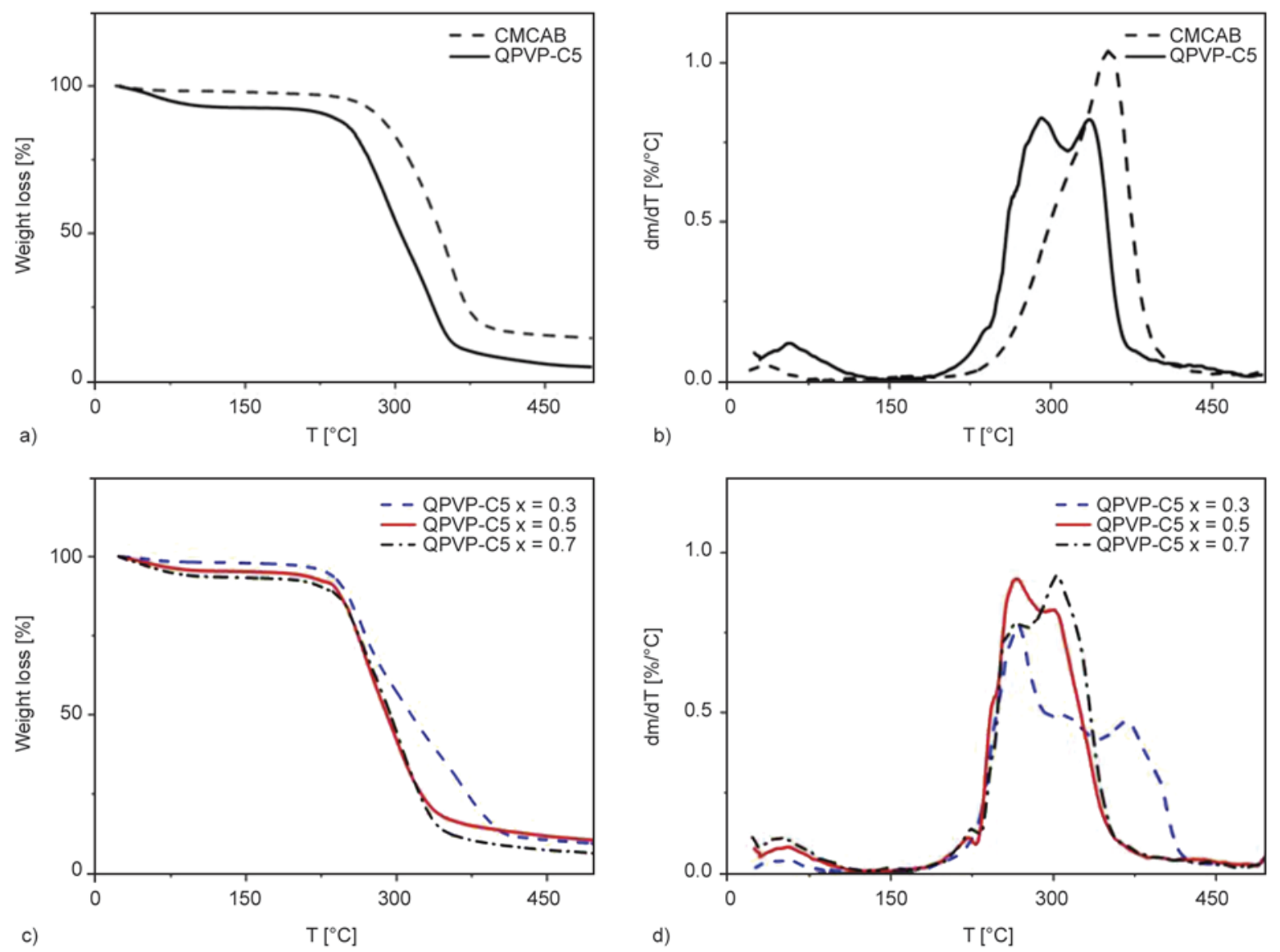

Figure 6. TG (a) and DTG (b) curves determined for pure CMCAB (dash line) and QPVP-C5 (solid line). TG (c) and DTG (d) curves obtained for CMCAB/QPVP-C5 blends with $x=0.3$ (dash line), 0.5 (solid line) and 0.7 (dash/dot line).

$N$-alkyl pyridinium) bromide decreases for alkyl side group larger than C6 [13]. The reason for this is a tilt in the geometry; when the alkyl chain is 6 carbons long or shorter, the dihedral angle is 0 or $180^{\circ}$, i.e. all the atoms lie in the same plane [24]. From the seventh atom forward the alkyl chain becomes crooked making a dihedral angle different from 0 or $180^{\circ}$ [24], shielding the positive charge.

The MIC and MBC of QPVP-C5 for both M. luteus and $E$. coli amounted to $11.7 \mu \mathrm{g} \cdot \mathrm{mL}^{-1}$. Such low concentration values indicated that QPVP-C5 has outstanding biocidal properties.

The bactericidal activity of pure CMCAB, pure QPVP-C5 and CMCAB/QPVP-C5 blends was correlated to the relative decrease of turbidity $(\Delta \tau)$ of $M$. luteus aqueous dispersion. Table 1 shows the $\Delta \tau$ values measured after interacting during $1 \mathrm{~h}$ with each polymeric film. In the case of pure QPVP-C5, chains dissolved in aqueous dispersion, presenting maximal $\Delta \tau$ values $(96 \pm 2 \%)$, which is in agreement with studies previously reported [16]. The $\Delta \tau$ values measured for the CMCAB/QPVP-C5 blends decreased with the decrease of QPVP-C5 content in the blends. The best antimicrobial effect was observed for the films of CMCAB/QPVP-C5 $x=$ 0.7 , with $\Delta \tau=66 \pm 5 \%$. In other words, the lower was the polycation content in the blends, the less bactericidal was the film. Additionally, the UV-Vis analysis indicated that the amount of leached QPVP-C5 was less than $1.5 \%$ of original amount used in the blend preparation, which corresponded to less than $15 \mu \mathrm{g} \cdot \mathrm{mL}^{-1}$. Considering that it is very close to the MIC and MBC found for QPVP-C5 against $M$. luteus and E. coli $\left(11.7 \mu \mathrm{g} \cdot \mathrm{mL}^{-1}\right)$, the biocidal properties of CMCAB and CMCAB/QPVP-C5 $(x=0.7)$ films were determined directly on the polymer. The CFU reduction was quantitatively determined for M. luteus and E. coli after $24 \mathrm{~h}$, as shown in Table 2. Against M. luteus neat CMCAB presented a modest $2 \log$ reduction, while the blend presented a remarkable $5 \log$ reduction. Against E. coli neat CMCAB had no biocidal activity, the CFU increased $1 \mathrm{log}$; however, the CMCAB/QPVP-C5 $(x=0.7)$ films caused $4 \log$ CFU reduction, evidencing the out- 
Table 2. CFU reduction determined for $M$. luteus and $E$. coli after $24 \mathrm{~h}$ contact with $\mathrm{CMCAB}$ and $\mathrm{CMCAB} /$ QPVP-C5 $(x=0.7)$ films

\begin{tabular}{|l|c|c|c|c|}
\hline \multirow{2}{*}{} & \multicolumn{4}{|c|}{ Micrococcus luteus ATCC 4698 [CFU/mL] } \\
\cline { 2 - 5 } & $\mathbf{0 ~ h}$ & $\mathbf{2 4} \mathbf{~ h}$ & $\begin{array}{c}\mathbf{l o g} \mathbf{C F U} \\
\text { reduction }\end{array}$ & $\begin{array}{c}\mathbf{\%} \\
\text { reduction }\end{array}$ \\
\hline CMCAB & $1 \cdot 10^{5}$ & $5.75 \cdot 10^{3}$ & 2 & 94.25 \\
\hline $\begin{array}{l}\text { CMC/QPVP-C5 } \\
(x=0.7)\end{array}$ & $1 \cdot 10^{5}$ & 0 & 5 & $>99.9$ \\
\hline Control & 0 & 0 & & \\
\hline & Escherichia coli ATCC 25922 & CFU/mL] \\
\cline { 2 - 5 } & $\mathbf{0 ~ h}$ & $\mathbf{2 4} \mathbf{h}$ & $\begin{array}{c}\text { log CFU } \\
\text { reduction }\end{array}$ & $\begin{array}{c}\text { \% } \\
\text { reduction }\end{array}$ \\
\hline CMCAB & $1.0 \cdot 10^{6}$ & $6.7 \cdot 10^{7}$ & - & - \\
\hline $\begin{array}{c}\text { CMC/QPVP-C5 } \\
(x=0.7)\end{array}$ & $1.0 \cdot 10^{6}$ & $7 \cdot 10^{2}$ & 4 & $>99.9$ \\
\hline Control & 0 & 0 & & \\
\hline
\end{tabular}

standing biocidal properties for Gram-positive and Gram-negative bacteria.

In order to gain insight about the orientation of pyridinium groups on the CMCAB/QPVP-C5 films, contact angle values $(\theta)$ were measured for pure $\mathrm{CMCAB}$ and blends with $x=0.17$ and 0.30 of QPVP-C5, as presented in Table 1. The $\theta$ values decreased from $(71 \pm 2)^{\circ}$ for pure $\mathrm{CMCAB}$ to $(65 \pm 3)^{\circ}$ for blends with $x=0.30$, indicating a slight increase in the wettability with increasing QPVP-C5 content in the blend. It was not possible to measure the contact angles for blends with $x \geq 0.5$ because the films became swollen by water droplets, invalidating the method. This behavior corroborates with the trend observed for the biocidal activities and supports the idea that upon increasing the QPVP-C5 content in the blends, the pyridinium groups tend to enrich the film surface.

\section{Conclusions}

Miscible blends of CMCAB/QPVP-C5 were prepared in ethanol, a good solvent for both polymers. The thermal stability of CMCAB/QPVP-C5 blends was superior to that of pure QPVP-C5. Upon increasing the content of QPVP-C5 in the blend, the surface wettability and antimicrobial properties against $M$. luteus and E. coli were favored, indicating surface enrichment by pyridinium groups. For practical purposes, CMCAB/QPVP-C5 blends could be coextruded with polyolefins, polystyrene, poly(methyl methacrylate), providing new materials with antimicrobial activity and good thermal stability, which can be used to manufacture daily items, like keyboards, doorknobs, handles, grips for supermarket trolleys and baskets, with protection against microbial infections transmitted by contact.

\section{Acknowledgements}

The authors acknowledge the Brazilian funding agencies CAPES Rede-NANOBIOTEC, CNPq and FAPESP for financial support.

\section{References}

[1] Edgar K. J., Buchanan C. M., Debenham J. S., Rundquist P. A., Seiler B. D., Shelton M. C., Tindall D.: Advances in cellulose ester performance and application. Progress in Polymer Science, 26, 1605-1688 (2001). DOI: $10.1016 / \mathrm{S} 0079-6700(01) 00027-2$

[2] El-Sakhawy M., Kamel S., Salama A., Sarhan H-A.: Carboxymethyl cellulose acetate butyrate: A review of the preparations, properties, and applications. Journal of Drug Delivery, 2014, 575969/1-575969/6 (2014). DOI: $10.1155 / 2014 / 575969$

[3] Obie R.: Improving holdout. US Patent 7026470 B2, USA (2006).

[4] Amim Jr. J., Petri D. F. S.: Effect of amino-terminated substrates onto surface properties of cellulose esters and their interaction with lectins. Materials Science and Engineering: C, 32, 348-355 (2012).

DOI: $10.1016 /$ j.msec.2011.11.004

[5] Amim Jr. J., Petri D. F. S., Maia F. C. B., Miranda P. B.: Ultrathin cellulose ester films: Preparation, characterization and protein immobilization (in Portuguese). Química Nova, 33, 2064-2069 (2010). DOI: $10.1590 / \mathrm{S} 0100-40422010001000011$

[6] Dallas P., Sharma V. K., Zboril R.: Silver polymeric nanocomposites as advanced antimicrobial agents: Classification, synthetic paths, applications, and perspectives. Advances in Colloid and Interface Science, 166, 119-135 (2011).

DOI: $10.1016 /$ j.cis.2011.05.008

[7] Knetsch M. L. W., Koole L. H.: New strategies in the development of antimicrobial coatings: The example of increasing usage of silver and silver nanoparticles. Polymers, 3, 340-366 (2011).

DOI: $10.3390 /$ polym 3010340

[8] Melo L. D., Palombo R. R., Petri D. F. S., Bruns M., Pereira E. M .D., Carmona-Ribeiro A. M.: Structureactivity relationship for quaternary ammonium compounds hybridized with poly(methyl methacrylate). ACS Applied Materials and Interfaces, 3, 1933-1939 (2011).

DOI: $10.1021 / \mathrm{am} 200150 \mathrm{t}$

[9] Vieira D. B., Lincopan N., Mamizuka E. M., Petri D. F. S., Carmona-Ribeiro A. M.: Competitive adsorption of cationic bilayers and chitosan on latex: Optimal biocidal action. Langmuir, 19, 924-932 (2003).

DOI: $10.1021 / 1 \mathrm{a} 026102 \mathrm{f}$ 
[10] Goy R. C., de Britto D., Assis O. B. D.: A review of the antimicrobial activity of chitosan (in Portuguese). Polímeros, 19, 241-247 (2009).

DOI: $10.1590 / \mathrm{S} 0104-14282009000300013$

[11] Wong S. Y., Li Q., Veselinovic J., Kim B-S., Klibanov A. M., Hammond P. T.: Bactericidal and virucidal ultrathin films assembled layer by layer from polycationic $\mathrm{N}$-alkylated polyethylenimines and polyanions. Biomaterials, 31, 4079-4087 (2010).

DOI: $10.1016 /$ j.biomaterials.2010.01.119

[12] Haldar J., An D., De Cienfuegos L. Á., Chen J., Klibanov A. M.: Polymeric coatings that inactivate both influenza virus and pathogenic bacteria. Procedings of the National Academy of Science of the United States of America, 103, 17667-17671 (2006).

DOI: $10.1073 /$ pnas.0608803103

[13] Tiller J. C., Liao C-J., Lewis K., Klibanov A. M.: Designing surfaces that kill bacteria on contact. Procedings of the National Academy of Science of the United States of America, 98, 5981-5985 (2001).

DOI: $10.1073 /$ pnas. 111143098

[14] Kügler R., Bouloussa O., Rondelez F.: Evidence of a charge-density threshold for optimum efficiency of biocidal cationic surfaces. Microbiology, 151, 13411348 (2005).

DOI: $10.1099 / \mathrm{mic} .0 .27526-0$

[15] Gozzelino G., Lisanti C., Beneventi S.: Quaternary ammonium monomers for UV crosslinked antibacterial surfaces. Colloids and Surfaces A: Physicochemical and Engineering Aspects, 430, 21-28 (2013).

DOI: $10.1016 /$ j.colsurfa.2013.03.061

[16] Silva R. A., Urzúa M. D., Petri D. F. S.: Lysozyme binding to poly(4-vinyl- $N$-alkylpyridinium bromide). Journal of Colloid and Interface Science, 330, 310-316 (2009).

DOI: $10.1016 /$ j.jcis.2008.10.087

[17] Amim Jr. J., Maia C. B. F., Miranda P. B., Urzúa M. D., Petri D. F. S.: Structural aspects of polyanion and hydrophobically modified polycation multilayers on hydrophilic or hydrophobic surfaces. Soft Matter, 8, 64626470 (2012).

DOI: $10.1039 / \mathrm{c} 2 \mathrm{sm} 25658 \mathrm{~d}$

[18] Blachechen L. S., Fardim P., Petri D. F. S.: Multifunctional cellulose beads and their interaction with gram positive bacteria. Biomacromolecules, 15, 3440-3448 (2014).

DOI: $10.1021 / \mathrm{bm} 5009876$

[19] Siedenbiedel F., Tiller J. C.: Antimicrobial polymers in solution and on surfaces: Overview and functional principles. Polymers, 4, 46-71 (2012). DOI: $10.3390 /$ polym4010046

[20] Muñoz-Bonilla A., Fernández-García M.: Polymeric materials with antimicrobial activity. Progress in Polymer Science, 37, 281-339 (2012). DOI: $10.1016 /$ j.progpolymsci.2011.08.005
[21] Muñoz-Bonilla A., Cerrada M. L., Fernández-Garcia M.: Polymeric materials with antimicrobial activity: From synthesis to applications. The Royal Society of Chemistry, Cambridge (2013).

[22] Simal-Gándara J.: Selection of can coatings for different applications. Food Reviews International, 15, 121137 (1999).

DOI: $10.1080 / 87559129909541180$

[23] Urzúa M. D., Ríos H. E.: Adsorption of poly(4-vinylpyridine) $N$-alkyl quaternized at the chloroform/water interface. Polymer International, 52, 783-789 (2003). DOI: $10.1002 /$ pi. 1148

[24] Oliveira A. M., Miranda P. B., Petri D. F. S.: Selfassembly of poly(4-vynil- $N$-alkylpyridinium) bromide onto silica: Effect of side-chain length on structural aspects at a molecular level. The Journal of Physical Chemistry C, 116, 18284-18291 (2012).

DOI: $10.1021 / j p 305606 \mathrm{k}$

[25] Adamson W. A.: Physical chemistry of surfaces. Wiley, Toronto (1980).

[26] Bergmeyer H. U., Bergmeyer J., Graß1 M.: Methods of enzymatic analysis. Verlag Chemie, Weinheim (1984).

[27] Clinical and Laboratory Standards Institute: Methods for dilution antimicrobial susceptibility tests for bacteria that grow aerobically; Approved standard-Tenth edition. CLSI document M07-A10, Wayne, USA (2015).

[28] Japanese Industrial Standard JIS Z 2801:2000. Antimicrobial products-Test for antimicrobial activity and efficacy (2000).

[29] Riaz U., Ashraf S. M.: Characterization of polymer blends with FTIR spectroscopy. in 'Characterization of polymer blends: Miscibility, morphology and interfaces' (eds.: Thomas S., Grohens Y., Jyotishkumar P.) Wiley, Weinheim, Vol 2, 509-538 (2014).

[30] Liu C., Xiao C.: Characterization of konjac glucomannan-quaternized poly(4-vinyl- $N$-butyl) pyridine blend films and their preservation effect. Journal of Applied Polymer Science, 93, 1868-1875 (2004). DOI: $10.1002 / a p p .20646$

[31] Liu C., Xiao C.: Characterization of films from chitosan and quaternized poly(4-vinyl- $N$-butyl) pyridine solutions. Journal of Applied Polymer Science, 92, 559-566 (2004).

DOI: $10.1002 /$ app. 20040

[32] Hiemenz P. C., Lodge T. P.: Polymer chemistry. CRC Press, Boca Raton (2007).

[33] Timofeeva L., Kleshcheva N.: Antimicrobial polymers: Mechanism of action, factors of activity, and applications. Applied Microbiology and Biotechnology, 89, 475-492 (2011).

DOI: $10.1007 / \mathrm{s} 00253-010-2920-9$ 